\title{
Controlling the Algorithms
}

\author{
Bjørn Erik Thon and Catharina Nes*
}

Where you have been, what you buy, who you know, how you drive, how your students rate you. These are just some of the factors on which Chinese authorities wish to base their citizens' credit rating. The objective of the Social Credit System is to create a national system that collects data from many different sources, both public and commercial, including social media. It is intended to encompass all citizens. In addition to performing a credit rating, the system can also be used by landlords, employers and potential sweethearts to assess what kind of person you are. The higher your score, the more opportunities open up. If you achieve more than 600 points, you can hire a car without paying a deposit. If you have more than 650 points, you can check out of hotels faster. And if you have more than 700 points, it becomes easier to get a visa to Singapore. The system will be in place by $2020{ }^{1}$

Access to vast amounts of data taken from social media, smart phones and wearable technology has resulted in a race to capture as much data on citizens as possible, in order to be able to predict their behaviour, wishes and needs. Every click, like and search gives businesses and government agencies access to data on users that they then feed into their algorithms.

Recent years have seen great progress in the field of artificial intelligence. Automated decision-making based on Big Data and machine learning is being applied to an increasing number of purposes. We are at a juncture where there is a lot at stake. We must take advantage of this critical moment to point the use of technology in a direction that safeguards the autonomy and integrity of the individual.

The Social Credit System developed by the Chinese government shows the powerful potential offered by Big Data for monitoring and controlling the population. Technology no longer sets a limit to the amount of data that can be collected, stored and analysed. The absence of technological or legal restrictions paves the way for Big Data solutions such as the Social Credit System. Big Data can be put to a wide range of uses, including fighting malaria and offering us the films and books we like. Neverthe-

\footnotetext{
Bjørn Erik Thon has been Commissioner in the Norwegian Data Protection Authority (DPA) since May 2010. Before his appointment, he served as the Norwegian Consumer Ombudsman for ten years. He has also held several political positions on local and national level for the Social Liberal Party. He has written several books. The last one, The American president's Norwegian daughter, was published in September 2014. Catharina Nes, Specialist Director at the Norwegian DPA. She has worked extensively with issues related to big data and profiling and has led the work on two reports on these topics: 'Big Data - privacy principles under pressure' (2013) and 'The Great Data Race - how commercial utilisation of data challenges privacy' (2015). Before she joined the DPA in 2008, she worked as a policy adviser at the European Commission, DG Information Society. For correspondence: <cane@datatilsynet.no>. DOI: $10.21552 / \mathrm{edpl} / 2017 / 1 / 5$

1 Hal Hodson, 'Inside China's plan to give every citizen a character score.' (New Scientist, 9 October 2015) <https://www.newscientist.com/ article/dn28314-inside-chinas-plan-to-give-every-citizen-a-character-score/> accessed 12 February 2017.
} 
less, the challenge posed by Big Data is that it, by its very nature, encroaches on important privacy principles, such as purpose limitation, relevance and data minimisation.

At the Norwegian Data Protection Authority, we have been working on issues related to Big Data for several years. ${ }^{2}$ During this period, our experience has been that powerful forces in both government authorities and commercial enterprises believe that the principles of purpose limitation and data minimisation have no justification in today's data-driven economy. I our opinion, however, a watering down of key privacy principles, in combination with more extensive use of Big Data, may have adverse consequences for the protection of privacy and other important values in society, such as freedom of expression and the unhindered exchange of ideas. We are therefore happy to see that the principles of purpose limitation and data minimisation retain their places in the General Data Protection Regulation (GDPR). These fundamental privacy principles constitute our guarantee that we will not be subjected to extensive profiling in an ever-widening array of new contexts.

In the future, an increasing number of decisions about our lives will be made by algorithms. Although we do not have systems like the Chinese Social Credit System in Europe, automated systems based on Big Data will nevertheless determine whether you are granted a mortgage to buy a new house, the social security benefits to which you are entitled and the medical treatment available to you when you are sick.

Intelligent systems which make decisions on the basis of vast amounts of data can make it difficult for citizens to investigate or question the decisions taken. The complex way in which the algorithms reach their results may put them beyond the reach of individuals' understanding. Technologically sophisticated systems may therefore become 'black boxes' that conceal the evaluations, uncertainties and choices made during the development of the models.

Intelligent systems make use of data which may, in some cases, be burdened by biases and distortions. There is therefore also a danger that automated decision-making systems may reinforce existing prejudices and stereotypes and amplify social exclusion. If decisions are made inside black boxes, unfair discrimination will be difficult to expose.

In order for individuals to provide data about themselves, they must feel confident that the systems are handling the data in an appropriate way and that the decisions taken are fair. The question is: can we trust fully automated systems? And just how transparent can an algorithm-based decision-making process be?

2 The Norwegian Data Protection Authority, 'Big Data - Privacy Principles Under Pressure' (September 2013) <https://www.datatilsynet.no/ globalassets/global/04 planer rapporter/big-data-engelsk-web.pdf> accessed 12 February 2017 and 'The Great Data Race. How commercial utilisation of personal data challenges privacy' (November 2015) <https://www.datatilsynet.no/globalassets/global/english/engelsk -kommersialisering-endelig.pdf> accessed 12 February 2017. 
As a regulatory authority, it is our obligation to ensure that automated decision-making systems based on Big Data respect the requirements of the law as regards legality, verifiability and fairness. To do this we need insight into the algorithms. We need to find a way to look inside the black box. Devising a method for doing so is a priority task for the Norwegian Data Protection Authority. It is, however, a demanding process to develop methods for validating and verifying systems that are so complex and inaccessible that even those who designed them are unable to explain how they work. The first step is to gain an understanding of the technology itself. The Norwegian Data Protection Authority uses a multi-disciplinary approach involving legal experts, technologists and social scientists. Our aim is to build expertise on artificial intelligence and its potential consequences for privacy.

New privacy legislation will be applicable in Europe in 2018. The legislation gives citizens new rights, businesses new obligations and regulatory authorities new tools. The Regulation introduces several new rights and obligations which will have major consequences for the use of Big Data and artificial intelligence. In the following, we will comment on the right to an explanation and the right to data portability, in particular.

If you are the subject of an automated decision, the GDPR grants you the right to explanation of the logic involved in the decision. This highlights the need for individuals to have the ability to understand how the algorithms work. But how can the inexplicable be explained? Even today, explaining how the premium payable on a motor vehicle insurance policy is calculated is difficult. A variety of factors are involved, such as age, number of years of driving experience, whether the driver lives in a town or in the country, whether she parks in a garage or in the street, etc. If the consumer also has agreed to install a chip in the car to monitor her driving behaviour, then speed, braking, use of indicators and so on will also be factored into the calculation. Explaining how the premium is calculated will still be possible, but it becomes virtually impossible if other, extraneous elements are also incorporated. These might include what the individual likes on social media or whether she regularly lets the battery on her mobile phone run down. We are eager to see how enterprises and governments will go about solving the problem of how to explain the logic behind automated decisions in a clear and comprehensible manner.

Big Data increases the imbalance between large enterprises on the one hand and individuals on the other hand. The enterprises that collect personal data are extracting ever-increasing added value from the analysis and processing of this information, not we who provide the information. Data portability is an important new right granted under the new Regulation, that may contribute to level out this current imbalance. It strengthens the consumer's right of ownership to her own data, allowing her to transfer data she has given from one company to another. As well as providing increased self-determination, data portability enables the consumer to exploit the value of the data financially. In Norway, a recently-formed insurance company, owned by a major supermarket chain, has a special offer for its customers: if a policyholder installs a black box in her car in order for her behaviour behind the wheel to be recorded, she 
will qualify for a $15 \%$ discount on her premium. In other words, the customer's behaviour behind the wheel is valued at $15 \%$ of the insurance premium.

Data portability could give the customer the right to take her driving performance data to a different company in order to obtain an even higher discount. Data portability could lead to heightened awareness about the value of our data. Let us hope that this new right will also become an important means of generating competition between suppliers to offer privacy-friendly services.

The use of Big Data and artificial intelligence is still in its infancy. Knowledge about the technology and its potential consequences for privacy is key if we are to influence the development in a direction that takes account of the fundamental rights of the individual. We would therefore like to compliment the EDPL for devoting an entire issue to Big Data, allowing us to further sharpen our insight and reach a higher level of reflection. This will better equip us to influence the use of Big Data, so that its use still safeguards privacy. 